\title{
RESILIENCE OF HISTORIC RESIDENTIAL AREAS SUBJECTED TO NATURAL DISASTERS
}

\author{
M. DRDÁCKÝ ${ }^{1 *}$, R. CACCIOTTI ${ }^{2}$ AND T. DRDÁCKÝ ${ }^{1}$ \\ ${ }^{1}$ Institute of Theoretical and Applied Mechanics of the Czech Academy of Sciences \\ Department of Heritage Science \\ Prosecká 76, 19000 Praha 9, Czech Republic \\ e-mail: drdacky@itam.cas.cz,drdackyt@itam.cas.cz, www.itam.cas.cz (*corresponding author) \\ ${ }^{2}$ Institute of Theoretical and Applied Mechanics of the Czech Academy of Sciences \\ Department of Diagnostics and Conservation of Monuments \\ Prosecká 76, 19000 Praha 9, Czech Republic \\ email: cacciotti@itam.cas.cz, www.itam.cas.cz
}

Keywords: historic city, risk mitigation, resilience, decision support tool

\begin{abstract}
The paper presents decision support tools developed for municipalities and historic city managers. These exploit the categorization of cultural heritage assets according to their vulnerability in disaster situations. A manual guiding individual cultural heritage owners, users and other citizens of historic areas provides advices on how to prevent or reduce damage and loss to cultural heritage. The recommendations cover pre-disaster, during as well as post-disaster situations and concern both built and moveable heritage. All measures are illustrated with examples taken during real disaster situations. The methodology has been tested during the international research project "ProteCHt2save" supported under the Interreg CE program.
\end{abstract}

\section{INTRODUCTION}

The concept of urban resilience indicates the ability of a city to withstand shocks to its survival. There exist various general definitions of resilience, such as the one by $\mathrm{C}$. E. Cloete [1]: resilience represents "the ability of a system to absorb changes without a transition to a different state". This can be expressed in other words as "the capacity of a system or object to absorb disturbances and reorganize while undergoing change so as to retain essentially the same function, structure, identity, and feedbacks" [2]. The concept of resilience has been further developed within a network supported by the Rockfeller Foundation, in 100 large cities. In this project, the urban resilience is defined as the capacity of individuals, communities, institutions, businesses and systems within a city to survive, adapt and grow no matter what kinds of chronic stresses and acute shocks they experience [3].

The resilience of residential areas exploits, for the study of its behaviour and change, an approach of so called complex adaptive systems [4,5,6]. Complex adaptive systems have various characteristics which are focused on the important properties related to change and the ability of a system to deal with change. First of all, the complex adaptive systems have histories allowing learning from experience, which is decisive for adaptability as well as 
resilience of a system.

The complex adaptive systems are alternatively also denoted multi-agent systems with its components called agents [7]. Agents are autonomous individual components with a capacity to play specific roles and an ability to interact with the others. Such interactions may result in effects of an emergent nature with important resilience impacts.

Residential areas with cultural heritage assets, referred to as historic residential areas, are considered as complex adaptive systems with specific characteristics. The resilience of built heritage, intended as a substance or a set of elements of a historic city, takes into account resilience of individual cultural heritage objects together with their interactive, dynamic, emergent and adaptive roles. Therefore, the resilience-building approach envisaged in the ProteCHt2Save project involves cultural heritage stakeholders into the development and materialization of measures reducing possible damage from natural hazards and climate change harming actions. It is based on the identification of controllable criticalities decisive for improved resilience of cultural heritage affected by natural hazard risks and the associated measures.

\section{DIMENSIONS OF RESILIENCE MEASURES}

The understanding of the multifaceted nature of the impact of disasters is an essential prerequisite for an adequate assessment of vulnerabilities of cultural heritage assets as well as for the design and implementation of effective risk reduction strategies in different hazard

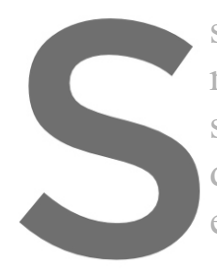
scenarios. Resilience m needs to be carefully summarised as follows: decision making an economic aspects. These
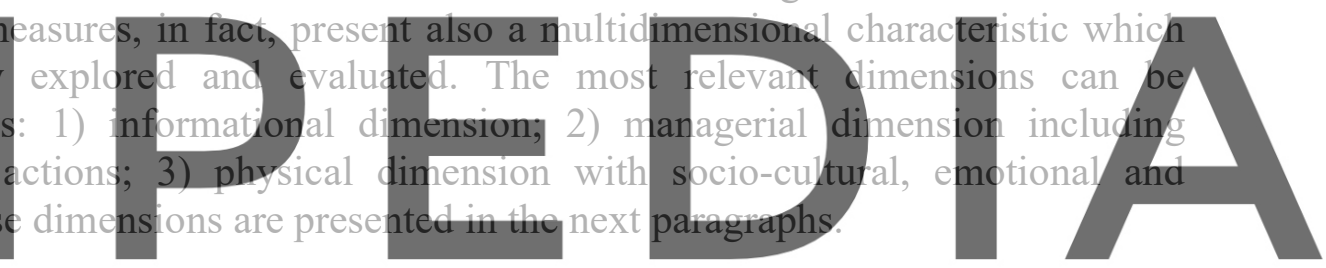

\subsection{Informational dimension}

Register for free at https//www.scipedia.com to download the version without the watermark The informational dimension is a crucial one as it refers to data gathering and processing activities and to the availability of risk related information enabling to determine the distribution and magnitude of hazards and vulnerabilities of cultural heritage systems. Reliable and solid data create the basis for planning and coordinating preventive measures, rescue actions as well as post-disaster activities. Typical examples are constituted by inundation maps which were introduced a decade ago as obligatory in all EU countries and still exhibit serious deficiencies from the cultural heritage point of view. They are mostly developed only for the river flood situations and typically do not contain information on the location of heritage assets and especially on the condition of such assets, which may affect approach to the resilience measures. Flash floods on small rivers and creeks due to heavy rains and storms are partly predictable using interactive maps which are available in some countries. Maps of flash flood inundation in plain like historic districts are mostly missing even though their occurrence is more frequent in the recent time. This is a challenge for development of future resilience methodologies. The problem has been recently identified as important after an assessment of the impact of heavy storms on some American cities [8] and it is also linked to information on a condition of infrastructure, namely rainwater drainage systems and channels. 
Maps have a strong potential for emergent response of communities in the historic residential areas. Even though remote sensing systems enable to a certain extent to include time effect and thus to slightly upgrade the 2D character of the hazard maps, there is still missing important information transforming visual data into 3D object or even 4D data suitable and necessary for temporary preventive measures, rescue as well as post disaster interventions and their evaluation. The authors believe that such a transformation can be achieved by a larger involvement of the human community potential. The following paragraphs present a possible approach focused mainly on the physical dimension of the resilience measures.

\subsection{Managerial dimension}

The managerial dimension includes those decision making processes and actions which dictate the major centrally managed resilience focused measures. However, any disaster's impact is usually unevenly distributed across the historic residential area territory. On the other hand in some situations an adoption of mitigating measures can also be effectively applied in a selective way. Therefore, a reasonable balance between centralized and individual resilience improving actions is desirable. In the ProteCHt2Save project, selected elements of cultural heritage have been categorized and ranked according to their vulnerability in hazard situations [9]. These are denoted as serious criticalities and exhibit a capacity to be controllable. A critical element can be defined as a factor or aspect of a CH system, intended as the ensemble of its

the determination of its Managerial critical

connected to the physical Managerial critical elements involving social and economic as well as polic
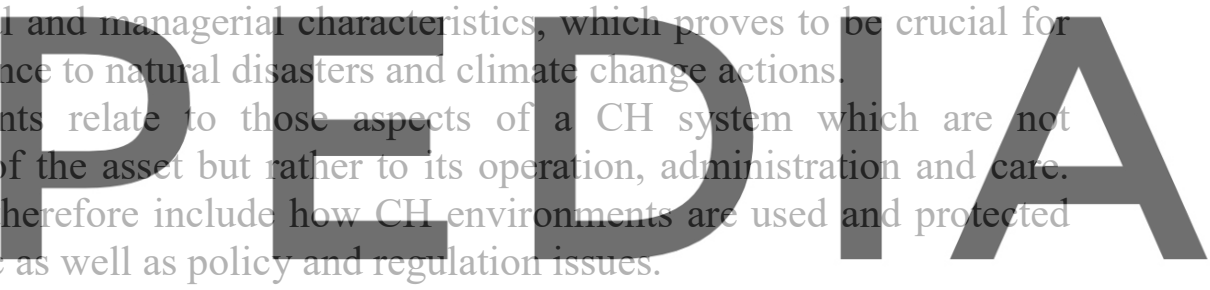

From the main findings of the project, transnational examples of managerial critical

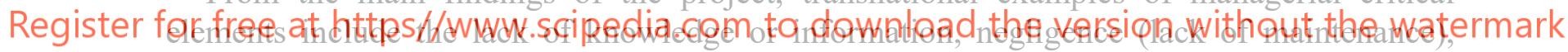
inadequate decision making, poorly designed emergency or post-disaster plans, missing funds etc. [10]. All these represent fundamental controllable features of a CH system which can be modified and adjusted by adopting appropriate management actions and measures. Each managerial critical element is strongly context-specific and requires an accurate assessment and thoughtful prioritisation in order to reduce the risks related to natural hazards and climate change and improve the resilience of the overall $\mathrm{CH}$ system.

\subsection{Physical dimensions}

The physical dimension of the measures relates to those aspects of a $\mathrm{CH}$ system involving its actual material composition and structural conditions. The sensitivity of historic structures and structural elements to weather and disasters is influenced by material and structural capability to resist exceptional loads and environments during disastrous situation. As mentioned for the previous dimension, also physical critical elements are significantly context-specific and require a thorough investigation of material characteristics and the general environmental situation (e.g. hydrogeological conditions) before being adequately evaluated. In some cases, in fact, it is not the historic structure itself that is sensitive to 
climatic conditions, but the surroundings and the supporting structure can also be affected. It should be emphasised that it exists a wide range of historic structures and materials, and also a wide range of types of damage. This makes it difficult to design widely applicable measures and unified methods. In this research, physical critical elements are analysed considering a ranking of historic structures, elements and situations according to their sensitivity to the effects of weather and natural disasters. In order to facilitate preventive protection and adaptation measures the authors suggested ranking of immovable heritage into five categories according to their vulnerability during individual natural disasters [11,12]. The ranking helps to identify the best practice and design decision making support tool. Criticalities are hence categorised as follows: a) flood, b) fire due to drought, 3) wind and 4) heavy rain group.

\section{RESILIENCE-BUILDING DECISION SUPPORT TOOLS}

The number of historic structures in historic residential areas endangered by natural or anthropogenic hazards is enormous and it is practically impossible to apply ideal permanent measures to upgrade all historic structures to a level corresponding contemporary knowledge and standards pertaining to the risks generated by earthquake, very strong windstorms, landslides or floods. Most historic structures that collapse fatally during natural disasters do so due to structural deficiencies, an inappropriate repair of minor faults or harmful structural modifications. Neglectful or inadequate maintenance of historic structures is a frequent phenomenon, to a large extent caused by the ignorance of the heritage owners or users

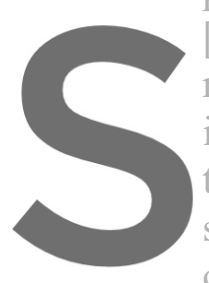
$[13,14]$. Even on the central level, knowing th
related preventive measures necessary can be
implemented. Therefore, in the ProteCHt2. Save
transnationally among the users in Austria, Hu
simplified version with an aim to mobilize s community resilience process.
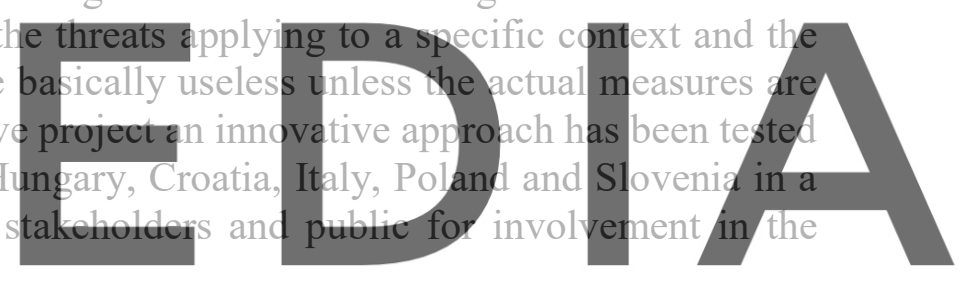

The novelty takes advantage of a combined non-centralized and centralized approach to the

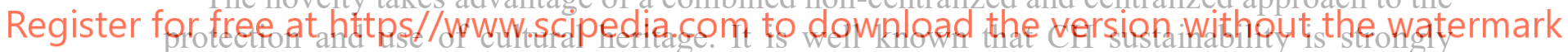

dependent on its condition as well as a mode of use. The both aspects are better controllable by the stakehoiders, nameiy owners, managers and users, than by centralized authorities.

The condition diagnostics of built heritage or the built environment is frequently compared to the medical health investigations. The presented approach learns from the success in the medicine in the recent decades when in relation to some diseases a self-investigation plays an important role in preventive treatment and mitigation of fatal cases. Therefore, the approach aims at development of tools for and a rise of awareness in a wide public concerning methods of indication of critical conditions or even defects which endanger heritage objects and decrease their sustainability and resilience in case of disasters.

The involvement of the "basic level" stakeholders has limitations in the necessary level of their knowledge. The developed tools increase substantially this level, however, in some situations a further step is necessary and then a more centralized approach is introduced. The approach thus develops a hierarchy of steps which significantly increase the scope of protection and resilience of heritage assets at reasonable costs, however, with a higher quality and longer sustainability. There is no limitation for the type of tangible cultural heritage in concern including intangible context when applicable. Moreover the full breadth of the 
"institutionalized" heritage is widened with a category of "family" heritage, i.e. the cultural heritage of mostly regional or local importance, which is the most endangered group during disaster situations and at the same time the category significantly influencing social strength and resilience capacity of communities. The family heritage involvement approach further increases a potential for safeguarding vanishing heritage, especially oral or unofficially stored on fragile media, e.g. mg tapes. It also substantially contributes to the complexity of a spatial scale of the resilience measures. The focus on resilience enhancement naturally supports the temporal scale of approaching the protection and conservation of cultural heritage. According to the modern resilience theories presented in the introduction only the communities with history can represent complex adaptive systems ready for successful resilience after disastrous events. The tools, briefly presented in the paragraphs below, are built as open to all forms of cultural heritage expressions as well as to the plurality of values attached to heritage. It has been explained above that one of the main principle accepts decentralization where possible and centralization where necessary or beneficial for the protection and conservation of cultural heritage.

\subsection{Manual of good and bad practices for managers}

The physical resilience of complex adaptive systems with cultural heritage assets to the impact of natural and man-made disasters can be improved by means of four basic
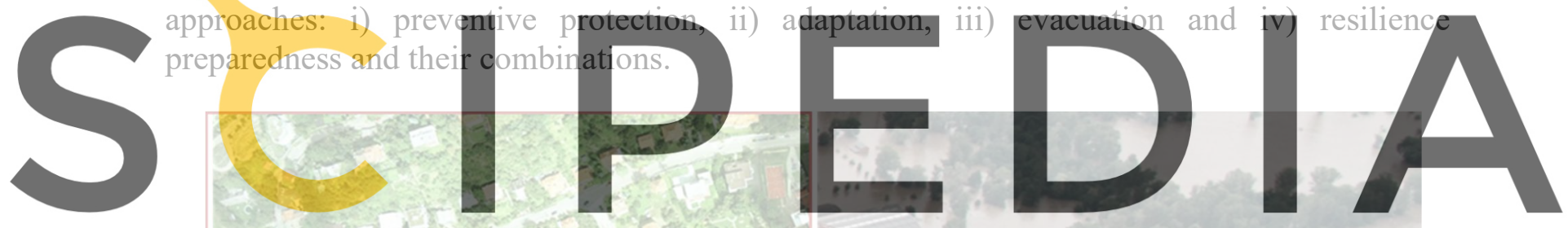

Register for free at https//www.scipedia.com to download the version without the watermark

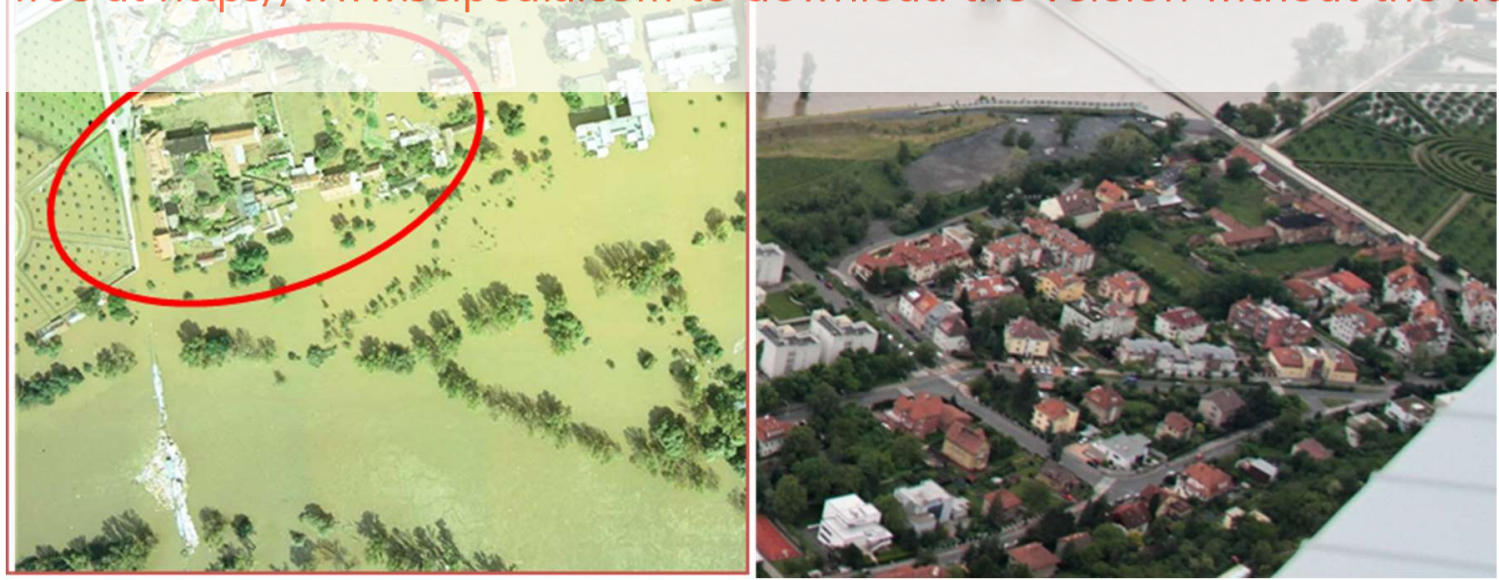

Figure 1: Left: unprotected historic Troja district (Prague, Czech Republic) during flood in the year 2002; right: the same area protected with a combined permanent and temporary wall during flood in the year 2013.

Preventive protection is cost demanding, not always feasible and it can sometimes lead only to partial benefits, such as for example in the case of threat of landslides. As far as the 
scale is concerned, preventive protection can be designed and implemented at territorial, building and material levels. Territorial protection, like barriers against flooding for example, could beneficially influence the resilience capacity of a $\mathrm{CH}$ system; however, at the same time, it should be considered that such large scale protection approach might induce a rather significant impact on values of the area with heritage assets, in case when stable structural measures are applied. It concerns namely landscape, visual and contextual values.

As an example let us present a case of a historic district in Prague Troja which was affected seriously during the flood in the year 2002 when water depth reached some eight meters. The so called historic "fishermen village" and an adjacent Baroque chateau were damaged, Fig. 1 left. Then the area has been protected by a combination of the permanent and temporary walls which effectively prevented inundation of the historic district during a later flood in the year 2013, Fig. 1 right. However, the natural contact and context between the village and the river was lost, Fig. 2. Fortunately, in this specific case the space between barriers and river is sufficiently large and could be developed for recreational activities substituting the historic attractions (sports, galleries, bars) less vulnerable to the impact of present threats.

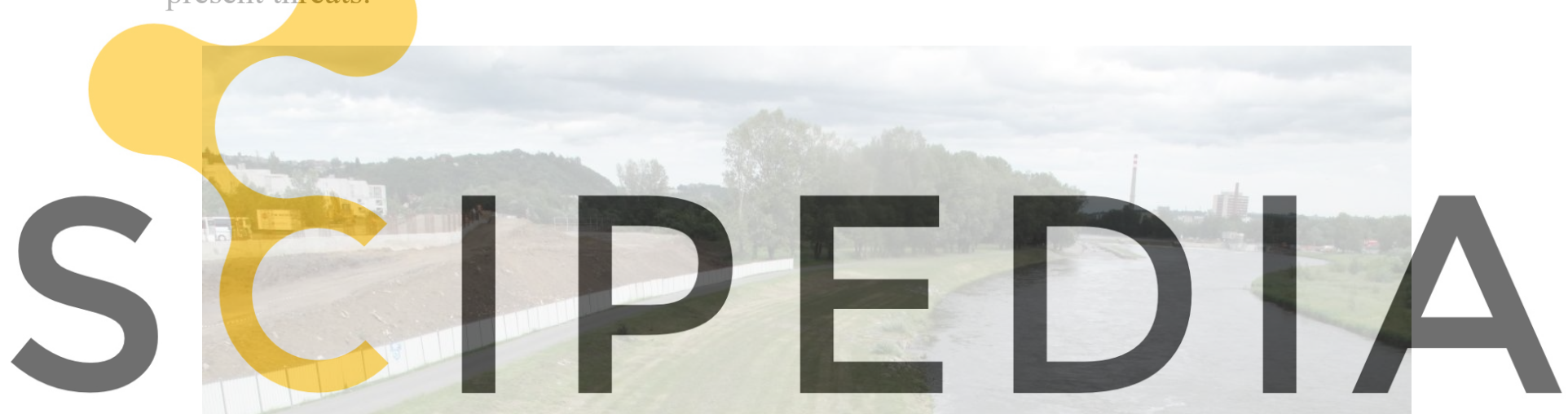

\section{Register for free at https//www.scipedia.com to download the version without the watermark}

Figure 2: Construction phase of the combined earth levee, permanent reinforced concrete wall with columns prepared for temporary metal barriers.

Preventive protection of buildings and complexes of buildings presents greater advantages when implemented using temporary measures, which are removable after the event. On the other hand, material protection is almost always irreversible, however for individual immovable artefacts or buildings could be very effective.

Adaptation is also cost demanding and can influence negatively the cultural heritage context and values. This approach is usually adopted in relation to climate induced risks or similar largely distributed threats and it needs wider campaigns and appropriate largely adopted financing.

Evacuation is the best protective measure suitable and applicable for moveable heritage. However, it needs planning, fast action and a safe space for temporary storage of the replaced artefacts. In the above mentioned case the river bank accommodates several objects with artefacts of cultural heritage value. One of them is so called "Troja Horse gallery" and Fig. 3 presents a schematic logistics for its evacuation. 


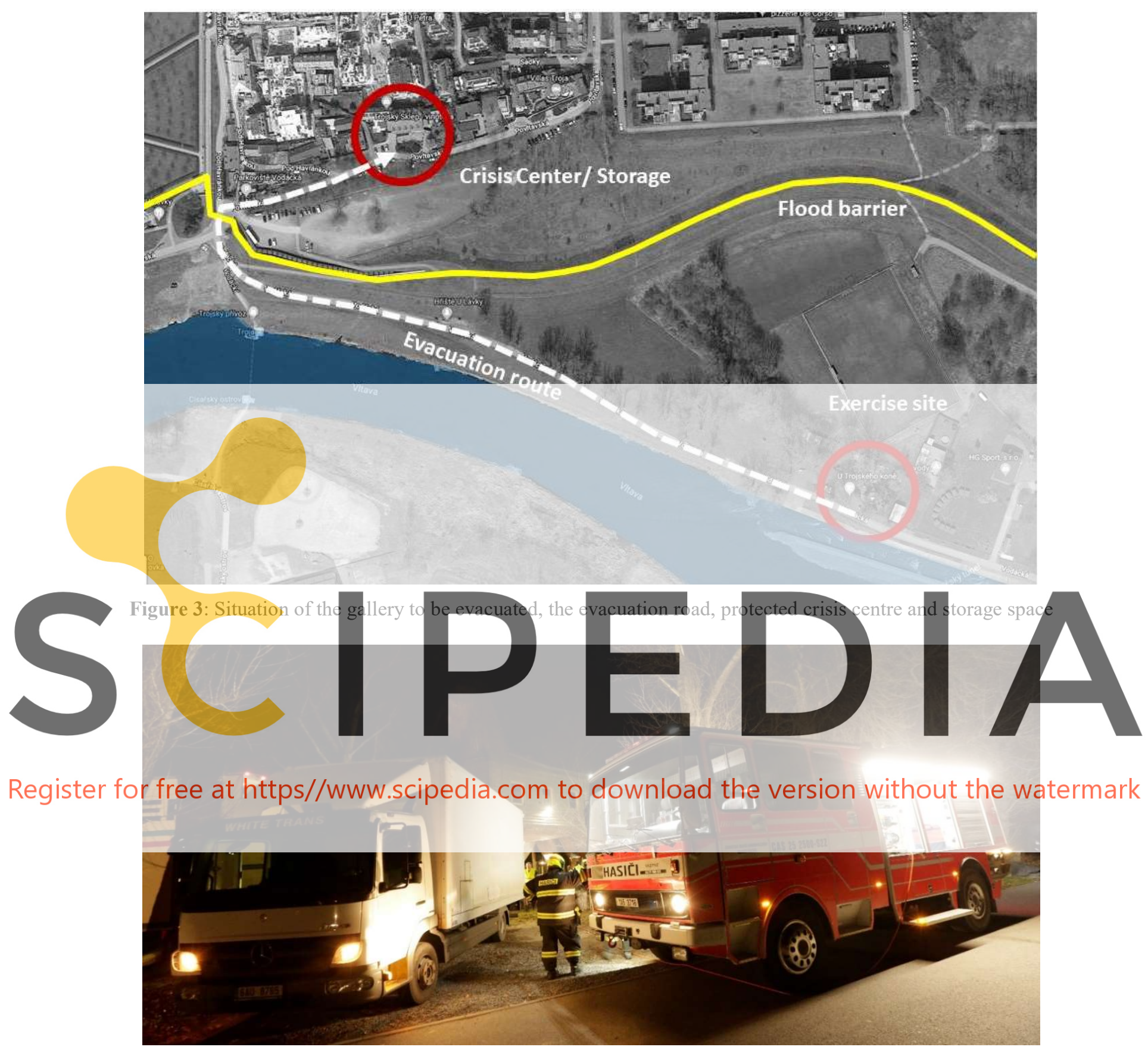

Figure 4: Evacuation of sculptures and paintings from the Troja Horse gallery - a training exercise

The effective application needs appropriate learning of local stakeholders and a regular training of the involved parties, Fig. 4. Resilience preparedness combines the all above mentioned approaches, involving to a larger extent the public and proving to be effective in complex situations such as in the protection of cultural heritage systems. Such resiliencebased approach is a core strategy for the INTERREG CE ProteCHt2save project, presenting a clear potential to be cost effective at ensuring high benefits [9]. 


\subsection{Handbook for owners}

The suggested centralised/non-centralised approach to resilience building, foresees the participation of non-technical stakeholders to preventive and rescue activities. Fur such reason a simple manual has been provided in order to help cultural heritage owners to identify controllable criticalities in their neighbourhood. Fig. 5 presents a typical page of the manual.

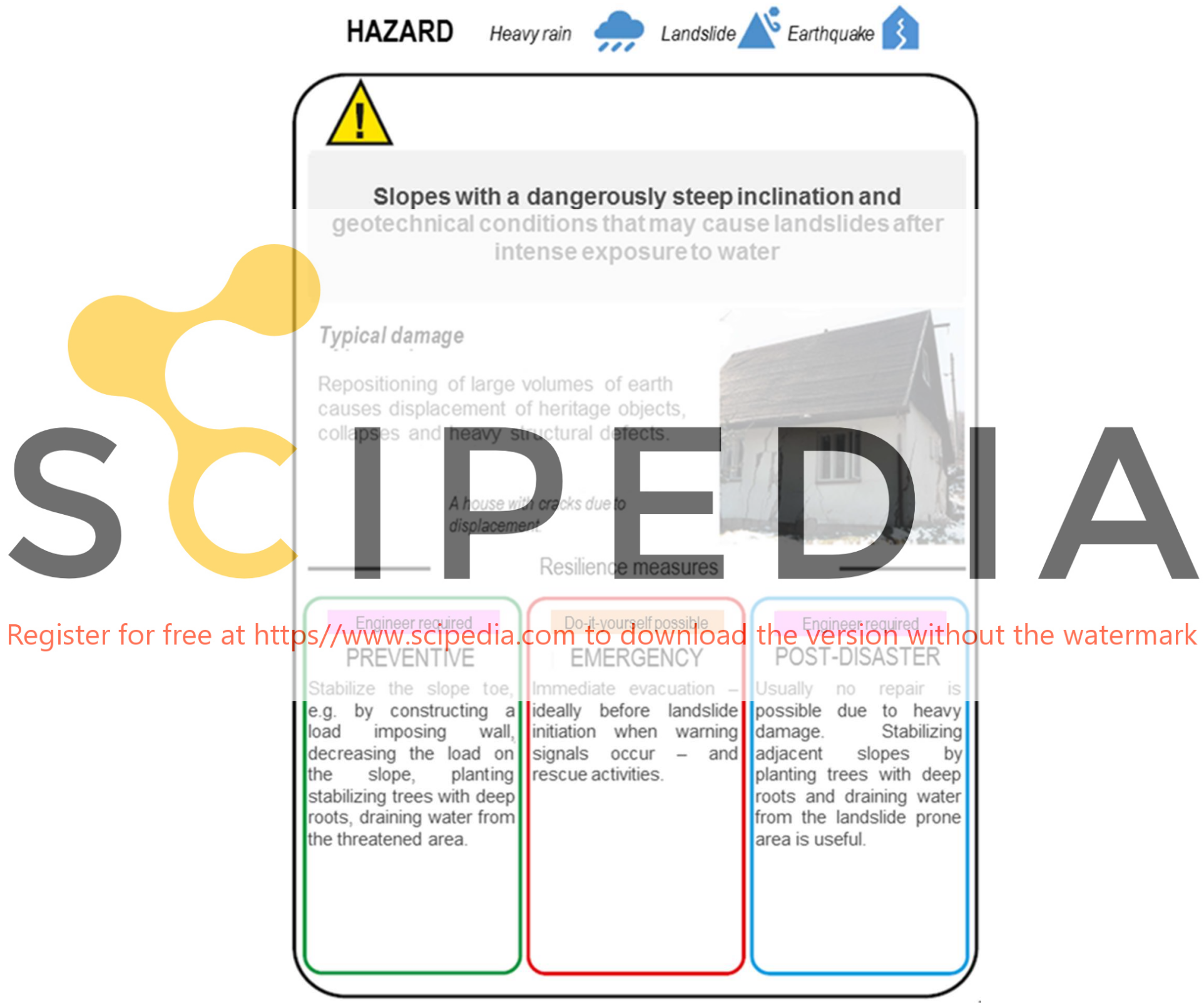

Figure 5: Example of one page of the manual

The page informs about one critical feature called "criticality" of a structure, building or object, which is observable by visual inspection. It is further illustrated with a typical damage or defect which the criticality can initiate or intensify. Then possible typical resilience 
supporting measures are suggested following the time periods of a disaster - preventive measures before the disaster starts, emergency actions during the disaster and post-disaster measures reducing damage due to mostly ignorance and negligence. Additionally, it is indicated which measures can be done by the owners or other stakeholders and which ones need skilled craftsmen and specialized professional in engineering or conservation. The pilot manual contains 40 pages of such guiding sets and covers problems typical for floods, windstorms, landslides, harsh weather situations. Use of the manual needs a short training and it is supported by consulting services, phone applications and an information system on damage of cultural heritage - MONDIS [15].

\section{CONCLUSIONS}

The approach outlined in this paper considers the resilience of the historic city as that of individual cultural heritage objects together with their interactive, dynamic, emergent and adaptive roles. It endorses the engagement of cultural heritage stakeholders into the development and materialization of measures reducing possible damage from natural hazards and climate change harming actions. This is based on the identification of controllable criticalities decisive for improved resilience of cultural heritage affected by natural hazard risks and the associated measures.

The understanding of the multifaceted nature of the impact of disasters is an essential prerequisite for an adequate assessment of vulnerabilities of cultural heritage assets. It helps designing and implentent this perspective, the rese as well present a multill evaluated, namely: 1 making and actions; 3 aspects. The resilience-building decision supp
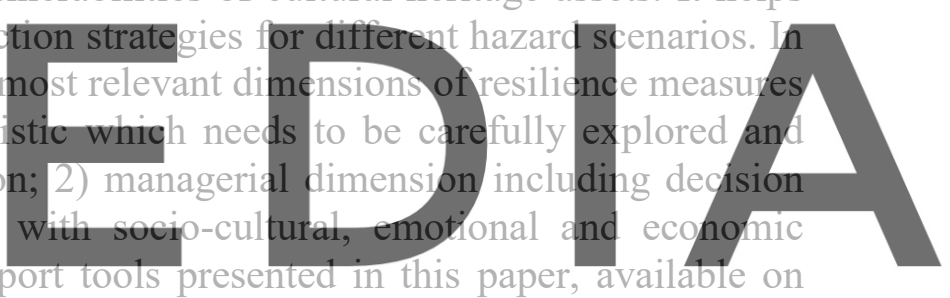
the ProteCHt2Save project website [9], include: the manual of good and bad practice and the

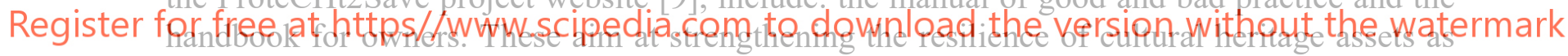
well as at enabling the participation of those users which are commonly excluded from the decision making processes, such as owners for the sake of determining a beneficial balance between centrally and non-centrally managed resilience measures.

Acknowledgements. This paper is based on the results of the research supported by the Interreg CE 1127 ProteCHt2save project (Risk assessment and sustainable protection of Cultural Heritage in changing environment) and the institutional project RVO 68378297.

\section{REFERENCES}

[1] Cloete, C.E. Assessing urban resilience. WIT Transactions on Information and Communication Technologies, Vol 44 (2012), W IT Press, www.witpress.com, ISSN 1743-3517 (on-line).

[2] Vale, L.J. and Campanella. T.J. The Resilient City. Oxford, University Press: New York, (2005).

[3] Rockefeller Foundation. 100 Resilient Cities. www.100resilientcities.org 
[4] Cilliers, P. Complexity and Post-modernism: Understanding complex systems. Routledge: London, ( 2008), p.45,.

[5] Nel, D. Exploring a complex adaptive system approach to the study of urban change. $\begin{array}{llll}\text { Thesis University of Pretoria, } & 015\end{array}$ https://repository.up.ac.za/handle/2263/56093.

[6] Wohl, Sh. Complex Adaptive Systems and Urban Morphogenesis: Analyzing and designing urban fabric informed by CAS dynamics. Thesis TU Delft, 2018 https://doi.org/10.7480/abe.2018.10.2397.

[7] Heylighen F., Cilliers, P. and Gershenson, C. Complexity and Philosophy. In: Jan Bogg and Robert Geyer (eds.): Complexity, Science and Society, Radcliffe Publishing: Oxford, (2007).

[8] National Academies of Sciences, Engineering, and Medicine 2019. Framing the Challenge of Urban Flooding in the United States. Washington, DC: The National Academies Press. https://doi.org/10.17226/25381.

[9] www.interreg-central.eu/Content.Node/ProteCHt2save.html

[10] Bonazza, A., Maxwell, I., Drdácký, M., Vintzileou, E., Hanus, Ch.: Safeguarding Cultural Heritage from Natural and Man-Made Disasters - A comparative analysis of risk management in the EU (with substantial contribution of Ch. Ciantelli, P. De Nuntiis, E. Oikonomopoulou, V. Nikolopoulou, S. Pospíšil, C. Sabbioni, P. Strasser). Luxembourg: Publications Office of the European Union, 2018, 187 p., ISBN 978-9279-73945-3 DOL:10.2766/224310 (catalogue) NC-05-17-059-EN-N.

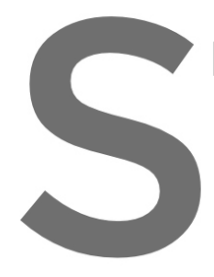

11] Sabbioni, C Brimblecombe, Jakiela, S., Drdáck Z., Saiz-Jimenez, Gomea-Bolez,
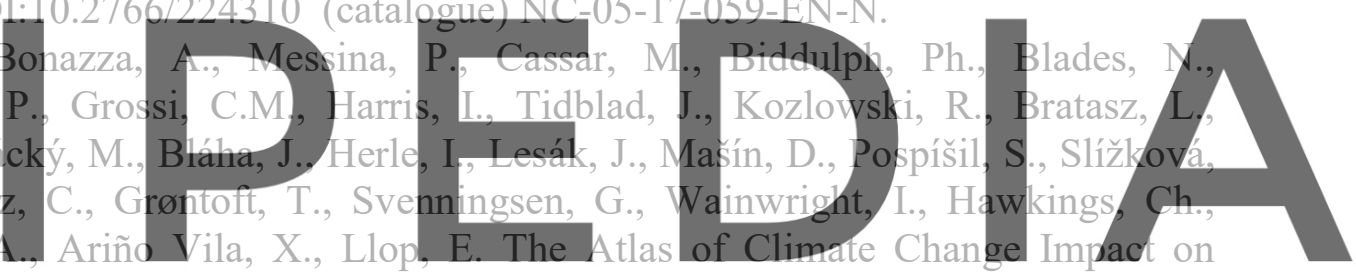

European Cultural Heritage - Scientific analysis and management strategies, ISBN-13:

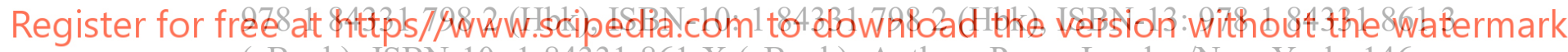
(eBook), ISBN-10: 184331861 X (eBook), Anthem Press, London/New York, 146 p., 2010

[12] Drdácký, M., Slížková, Z. Structural strategies and measures reducing flood action on architectural heritage. In "Risk Analysis VIII" (C.A. Brebbia - ed.), WIT Transactions on Information and Communication Technologies, Vol 44, WIT Press, Ashurst, Southampton, UK, 2012, pp. 249-259, doi:10.2495/RISK120221.

[13] Drdácký, M., Herle, I., Pospíšil, S., Slížková, Z. Protecting cultural heritage against natural hazards, in Keynote Papers "Seismic protection of cultural heritage", Proc. of the 2nd WCCE-ECCE-TCCE Joint Conference, Antalya, ISBN 978-605-01-0188-1, Turkish Chamber of Civil Engineers, Ankara, 2011, pp. 103-122

[14] Drdácký, M.: The vulnerability and resilience of historic structures. Transsylvania Nostra. (2017) 11: 8-12.

[15] Cacciotti, R., Blaško, M., Valach, J. A diagnostic ontological model for damages to historical constructions, J. Cult Her (2015) 16: 40-48. 